\title{
EFEITO DO TEMPO DE ARMAZENAGEM DE RAÇÕES AVÍCOLAS NO DIMENSIONAMENTO DE SILOS
}

\author{
JOSÉ P. LOPES NETO ${ }^{1}$, JOSÉ W. B. DO NASCIMENTO ${ }^{2}$, VALNEIDE R. DA SILVA ${ }^{3}$
}

RESUMO: Dentre os fatores que afetam o fluxo de produtos sólidos, o tempo de armazenagem destaca-se por favorecer a formação de arcos coesivos. Dessa forma, esta pesquisa teve como objetivo determinar as propriedades de duas rações avícolas, classificá-las quanto à escoabilidade em função do tempo de consolidação e analisar seus efeitos em tremonhas metálicas. Para isso, foram utilizados aparelho de cisalhamento direto "Jenike Shear Cell", bancada de consolidação e duas superfícies de parede. Para o índice de fluxo e diâmetro mínimo do orifício de descarga, adotou-se a metodologia de Jenike. Para o ângulo da tremonha cônica, recorreu-se à metodologia de Enstad. Pode-se afirmar que as duas rações possuem fluxo do tipo fácil, sem variação para os tempos de armazenagem estudados. A rugosidade das paredes apenas afetou a inclinação da tremonha, enquanto os resultados de orifício de descarga não foram afetados pela variação das propriedades das rações nas paredes e nos tempos analisados.

PALAVRAS-CHAVE: consolidação, índice de fluxo, tremonha.

\section{EFFECT OF TIME STORAGE OF POULTRY RATIONS FOR SILOS DESIGN}

ABSTRACT: Among the factors that affect the flow of solid products, the storage time stands out being responsible for promoting the appearance of cohesive arches. Thus, the present research had as objective to determine the properties of two poultry types of ration, classifying them through the flowability depending on the consolidation time and analyzing their effects in metallic hoppers. For this purpose, a direct shear apparatus known as 'Jenike Shear Cell', a consolidation bench and two wall surfaces were used. For the index flow and minimum diameter of the discharge hole, it was used the Jenike's methodology. For conical hopper angle the Enstad's methodology was adopted. It can be affirmed that the two types of ration presented easy flow, not depending on the storage period. The roughness walls affected only the hopper slope, while the results of the discharge hole were not affected by the variation of the properties of the types of ration on the wall surfaces and elapsed times studied.

KEYWORDS: consolidation, index flow, hopper.

\section{INTRODUÇÃO}

O fluxo de produtos sólidos pode ser descrito como o movimento relativo entre partículas e superfície das paredes das estruturas de armazenagem. Com o surgimento de uma gama de novos produtos industriais armazenáveis, é de extrema importância que o tipo de fluxo desenvolvido por esses produtos seja conhecido a fim de que se estabeleçam, de forma segura, as mais adequadas condições de transporte, armazenagem e manuseio.

JULIANO et al. (2006) afirmam que as propriedades de fluxo são responsáveis por determinar o comportamento dos produtos armazenáveis em silos, tremonhas e em transportadores, sendo possível maximizar operações como descargas, transilagem, dosagem e empacotamento, e evitar inseguranças quanto ao tipo de fluxo e obstruções de descarga.

\footnotetext{
${ }^{1}$ Eng ${ }^{\circ}$ Agrícola, Prof. Dr., Unidade Acadêmica de Agronomia e Tecnologia de Alimentos, Universidade Federal de Campina Grande, Câmpus de Pombal, Rua Coronel João Leite, 517, Pombal - PB, Fone: (0XX83) 3431.2376, neto@ ccta.ufcg.edu.br

${ }^{2}$ Eng $^{\mathrm{o}}$ Agrícola, Prof. Dr., Unidade Acadêmica de Engenharia Agrícola, Universidade Federal de Campina Grande, Câmpus de Campina Grande, Rua Aprígio Veloso, 882, Campina Grande - PB, Fone: (0XX83) 3330.1482, wallace@ deag.ufcg.edu.br

${ }^{3}$ Eng ${ }^{\mathrm{a}}$ Agrícola, mestranda em Engenharia Agrícola, Universidade Federal de Campina Grande, Câmpus de Campina Grande, Rua Aprígio Veloso, 882, Campina Grande - PB, Fone: (0XX83) 3330.1482, ravl707@ yahoo.com.br

Recebido pelo Conselho Editorial em: 18-7-2007

Aprovado pelo Conselho Editorial em: 3-9-2009
} 
Segundo GUAN \& ZHANG (2005), os problemas relacionados aos silos podem ser classificados em duas categorias: falhas estruturais (flambagem, colapso estrutural, problemas de fundação) e falhas funcionais (formação de arcos, efeito tubo, segregação e explosão). Dentre os principais problemas funcionais, destaca-se a formação de arcos coesivos capazes de restringir parcial ou completamente a descarga, estando sua ocorrência relacionada às geometrias dos silos e às tremonhas (DRESCHER et al., 1995).

As propriedades dos produtos armazenáveis, condições ambientais como pressão, temperatura e umidade (TEUNOU et al., 1999) e o tempo de armazenagem também são fatores que podem afetar consideravelmente o tipo de fluxo dos sólidos armazenáveis e favorecer a formação de arcos coesivos.

JENIKE (1964) foi um dos principais pesquisadores no estudo do comportamento de sólidos em silos e o pioneiro em definir os tipos de fluxo durante a descarga, sendo denominado de fluxo de massa (Figura 1.a) aquele em que o produto entra em movimento em todas as partes do silo no descarregamento, e fluxo de funil (Figura 1.b) aquele em que apenas uma parte do produto entra em movimento através de um canal vertical, ficando a outra parte em condição estática.

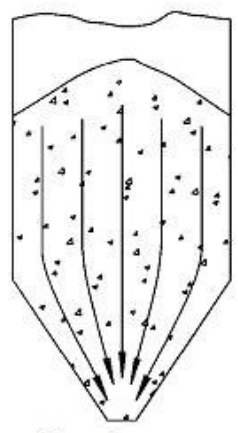

Fluxo de massa

a)

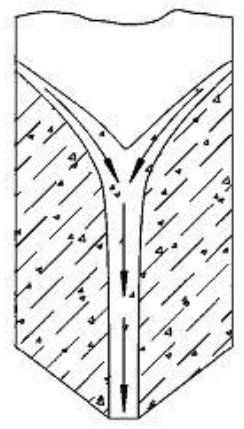

Fluxo de funil

b)

FIGURA 1. Tipos básicos de fluxo. Basic flow pattern.

JENIKE (1964) desenvolveu um aparelho de cisalhamento para a determinação das propriedades de fluxos dos produtos armazenáveis, denominado "Jenike Shear Cell”, sendo possível construir gráficos de tensão normal "versus" cisalhamento, nos quais são traçados círculos de tensões de "Mohr" responsáveis por determinar a Tensão Principal de Consolidação $\left(\sigma_{\mathrm{p}}\right)$ e a Tensão Não Confinada de Deslizamento $\left(\mathrm{f}_{\mathrm{C}}\right)$ para cada produto (Figura 2). Assim, são traçadas retas denominadas de Lugares Geométricos de Deslizamento (LGD) donde são obtidos os valores de ângulo de atrito interno (Ø), ângulo efetivo de atrito interno $(\delta)$ e Coesão $(C)$.

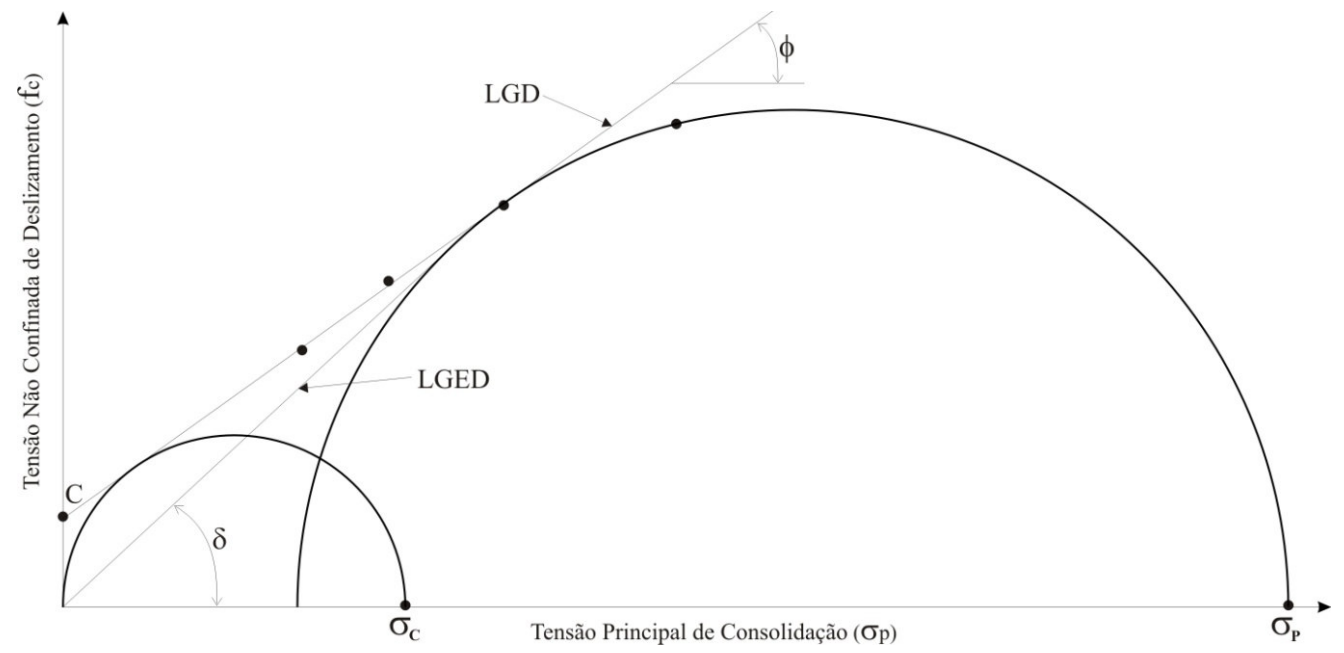

FIGURA 2. Círculos de tensões de Mohr. Mohr's stress circle. 
Outra propriedade importante na caracterização do fluxo de um produto é sua Função Fluxo (FF), representando a habilidade do sólido em fluir por meio de gravidade e/ou outras forças (KHANAM \& NANDA, 2005), e sua inclinação define o grau de escoabilidade desse produto (Figura 3(a)); por meio da interceptação de FF pelo fator fluxo da tremonha (ff), é possível determinar a Tensão Crítica Mínima $\left(\sigma_{\mathrm{cr}}\right)$ a fim de evitar a formação de obstrutores de descarga (Figura 3(b)).

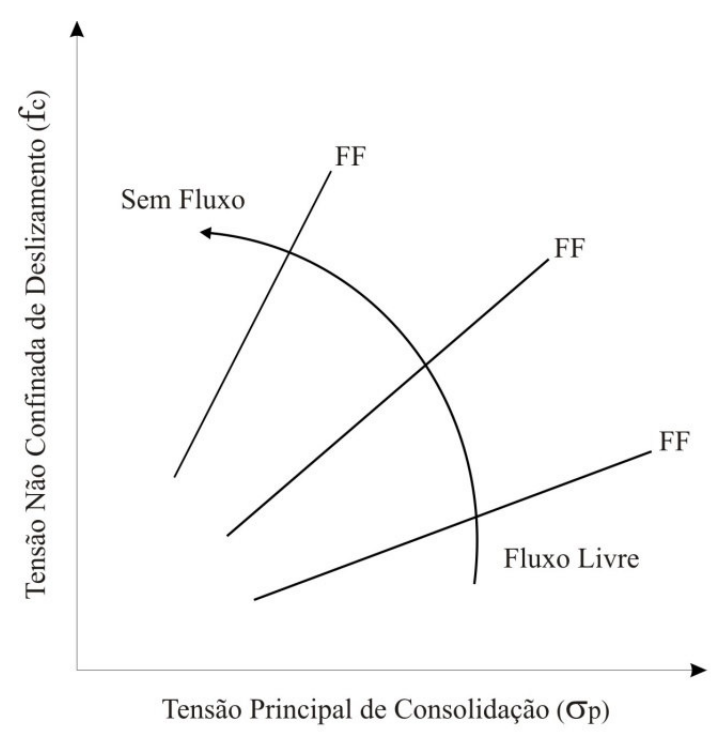

a)

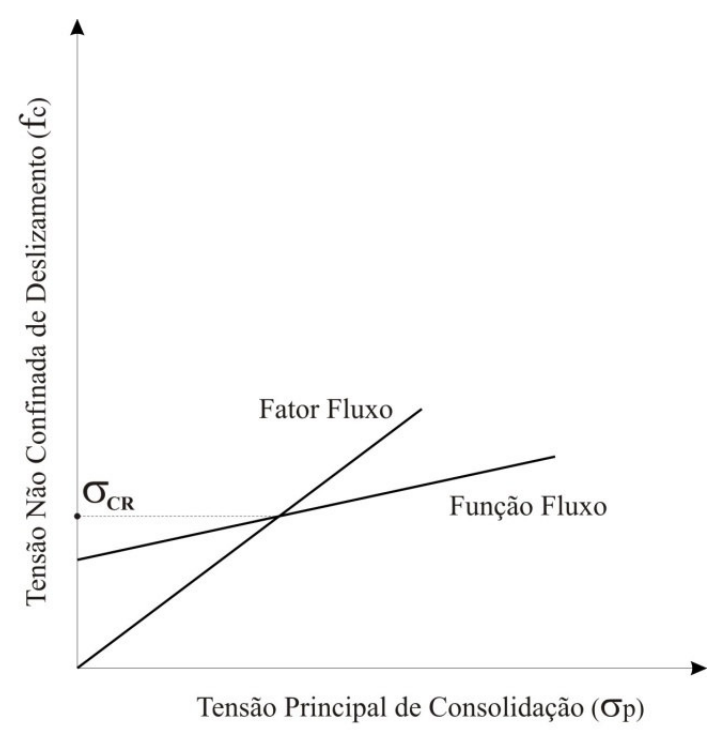

b)

FIGURA 3. Função Fluxo. Flow Funtion.

Apresentam-se, neste trabalho, a determinação das propriedades físicas e de fluxo de duas rações avícolas para o dimensionamento de silos, sua escoabilidade em função do tempo de consolidação e análise de seus efeitos nas características geométricas de tremonhas para dois materiais de parede.

\section{MATERIAIS E MÉTODOS}

Foram testadas duas rações avícolas comerciais, sendo denominada de Ração A aquela destinada à fase inicial, e de Ração B aquela para a fase final de crescimento das aves. $\mathrm{O}$ teor de umidade (TU) foi determinado pela diferença na pesagem de amostras de $10 \mathrm{~g}$ de cada produto antes e após a secagem em estufa a $105^{\circ} \mathrm{C} \pm 3{ }^{\circ} \mathrm{C}$ por $24 \mathrm{~h}$. As amostras foram analisadas em triplicata para cada ração, sendo o resultado final expresso em base úmida (bu). A dimensão média das partículas (dm) foi determinada conforme ABNT (1987). Para a determinação do teor de gordura das rações (TG), adotou-se o método de RANDALL (1974).

O procedimento adotado para a determinação das propriedades de fluxo das rações foi o recomendado pela BRITISH MATERIALS HANDLING BOARD (1985), utilizando o Aparelho de Cisalhamento Direto Translacional (Jenike Shear Cell) (Figura 4). O método adotado para o ensaio de consolidação foi similar ao cisalhamento instantâneo. Entretanto, após o pré-cisalhamento de cada amostra, as células foram transferidas para a bancada de consolidação (Figura 5) onde permaneceram por $12 \mathrm{~h}$ sob ação de cargas predefinidas (Tabela 1). Após esse período, as células foram novamente transferidas para o aparelho de cisalhamento para a continuação dos testes. A Bancada de Consolidação utilizada possui capacidade para seis células, carregadas independentemente. 

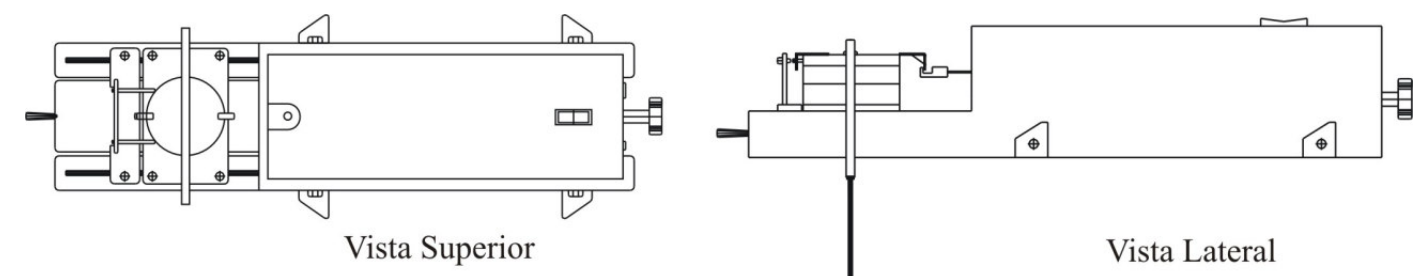

FIGURA 4. Aparelho de cisalhamento direto. Direct shear apparatus.

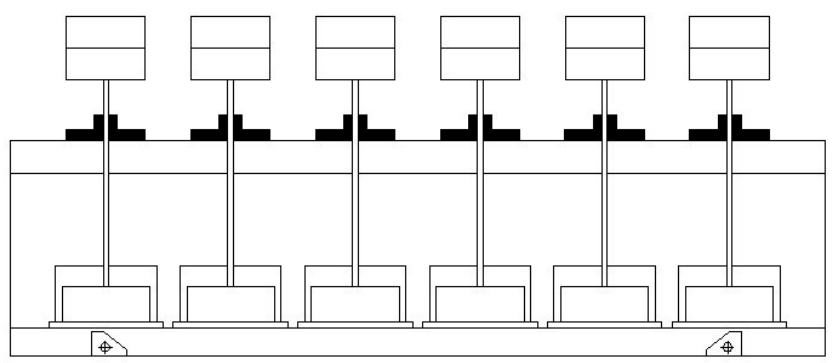

FIGURA 5. Bancada de consolidação. Consolidation bench.

TABELA 1. Níveis de carga de cisalhamento e de consolidação utilizados nos ensaios. Loads in consolidation and shear tests used.

\begin{tabular}{cccc}
\hline Pré-cisalhamento (N) & \multicolumn{3}{c}{ Cisalhamento (N) } \\
\hline 100 & 70 & 50 & 35 \\
70 & 50 & 35 & 20 \\
50 & 35 & 20 & 10 \\
\hline
\end{tabular}

Para a determinação do ângulo de atrito com a parede $\left(\emptyset_{\mathrm{w}}\right)$, foram adotados o mesmo equipamento e a mesma célula de cisalhamento, mas com a substituição de seu anel inferior pela amostra do material da parede, como também outros níveis de carga $(50 \mathrm{~N}, 40 \mathrm{~N}, 30 \mathrm{~N}, 20 \mathrm{~N}, 10 \mathrm{~N}$ e 4,4 N). As superfícies utilizadas nos ensaios foram aço liso e rugoso por serem os materiais mais utilizados na construção de silos.

Para a obtenção do índice de fluxo $\left(\mathrm{ff}_{\mathrm{c}}\right)$, utilizou-se o valor médio das razões entre $\sigma_{\mathrm{p}}$ e $\mathrm{f}_{\mathrm{C}}$, classificando cada produto ensaiado de acordo com os índices da Tabela 2, enquanto o orifício de descarga mínimo (D) foi calculado conforme método de Jenike (1964), como sendo:

$$
\mathrm{D}=\frac{\mathrm{H}(\theta) \sigma_{\mathrm{cr}}}{\gamma}
$$

em que,

$\mathrm{H}(\theta)$ - função do ângulo de inclinação da tremonha;

$\sigma_{\mathrm{cr}}$ - tensão crítica não confinada, e

$\gamma$ - peso específico consolidado.

TABELA 2. Índice de fluxo (JENIKE, 1964). Index flow (JENIKE, 1964).

\begin{tabular}{cc}
\hline Tipos de Fluxo & Índice de Fluxo $\left(\mathrm{ff}_{\mathrm{c}}\right)$ \\
\hline Sem fluxo & $\mathrm{ff}_{\mathrm{c}}<1$ \\
Muito coesivo & $1<\mathrm{ff}_{\mathrm{c}}<2$ \\
Coesivo & $2<\mathrm{ff}_{\mathrm{c}}<4$ \\
Fácil & $4<\mathrm{ff}_{\mathrm{c}}<10$ \\
Livre & $\mathrm{ff}_{\mathrm{c}}>10$ \\
\hline
\end{tabular}


Para a determinação do ângulo de inclinação mínimo da tremonha cônica com a horizontal $(\theta)$, adotou-se a abordagem descrita por ENSTAD (1981). Todos os ensaios foram realizados em laboratório, com temperatura ambiente e umidade relativa do ar constantes a $24{ }^{\circ} \mathrm{C}$ e $65 \%$, respectivamente.

\section{RESULTADOS E DISCUSSÃO}

Na Tabela 3, estão dispostos o teor de umidade (TU), o teor de gordura (TG) e a dimensão média das partículas $(\mathrm{dm})$ das duas rações analisadas. Conforme se observa na Tabela, as propriedades físicas das duas rações são muito semelhantes, sem grandes variações em suas propriedades.

TABELA 3. Propriedades físicas das rações. Physical properties of rations.

\begin{tabular}{cccc}
\hline Ração & TU (\%) & dm $(\mathrm{mm})$ & TG $(\%)$ \\
\hline A & 12 & 0,6 & 7,2 \\
B & 13 & 0,6 & 7,0 \\
\hline
\end{tabular}

Na Tabela 4, encontram-se os resultados das propriedades instantâneas e de consolidação de fluxo das duas rações, sendo que o peso específico consolidado $(\gamma)$, o ângulo de atrito interno $(\varnothing)$ e o ângulo efetivo de atrito interno $(\delta)$ apresentados em seus valores máximos e mínimos, possibilitando, assim, o projeto de silos por meio do Método dos Estados Limites (AUSTRALIAN STANDARD 3774, 1996).

TABELA 4. Propriedades de fluxo das rações. Flow properties of rations.

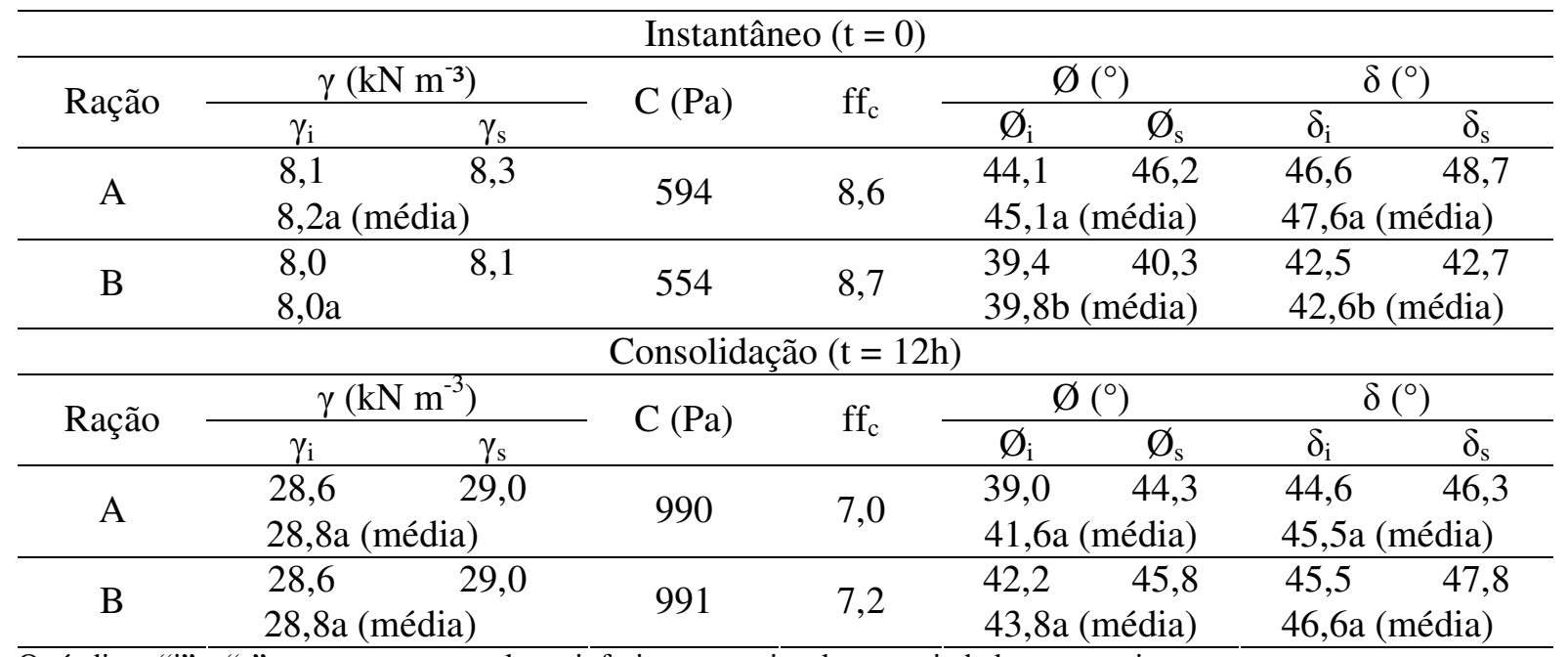

Os índices “i” e "s" representam os valores inferior e superior das propriedades, respectivamente.

Em análise ao peso específico, pode-se afirmar que não houve diferença estatística entre as médias das duas rações para os tempos iguais a zero e $12 \mathrm{~h}$. Entretanto, entre os dois períodos de armazenagem, notou-se aumento de 3,5 vezes para as duas rações. Isso pode ser comprovado pelo valor de coesão de consolidação duas vezes maior para a condição instantânea.

Uma das explicações para esse efeito é a capacidade de um produto tornar-se gradualmente mais compacto sob ação de consolidação devido à existência de maior número de regiões de contato oriundas do rearranjo de partículas e de deformações plásticas sofridas.

Isso conduz a maiores interações entre as forças envolvidas no sistema e, assim, maiores valores de coesão com o decorrer do tempo (MALBY et al., 1993). Outro fator importante é que as interações entre forças envolvidas na coesão do produto podem requerer determinado tempo para se desenvolverem e, dessa forma, a coesão sobre a ação do tempo pode tornar-se gradualmente maior, 
influenciando consideravelmente no peso específico de um sólido armazenável (TEUNOU \& FITZPATRICK, 2000).

Em respeito ao índice de fluxo $\left(\mathrm{ff}_{\mathrm{c}}\right)$, as duas rações podem ser classificadas como de fluxo do tipo fácil $\left(4<\mathrm{ff}_{\mathrm{c}}<10\right)$ e, apesar da grande variação de $\gamma$ e $\mathrm{C}$ entre os tempos analisados, não foi notado efeito expressivo do tempo de consolidação sobre os valores de $\mathrm{ff}_{\mathrm{c}}$, indicando que, para as rações analisadas, o período de consolidação de $12 \mathrm{~h}$ foi insuficiente para alterar de forma expressiva seus níveis de escoabilidade.

No entanto, uma variável que interfere significativamente no tipo de fluxo é a dimensão das partículas. TEUNOU et al. (1999), ao analisarem a escoabilidade de leite em pó, farinha e chás, concluíram que, em geral, produtos com dimensões de partículas maiores que 0,2 $\mathrm{mm}$ apresentam fluxo do tipo fácil a livre. Em contrapartida, sabe-se que produtos com dimensões de suas partículas reduzidas apresentam problemas de escoamento, pois a área da superfície da partícula por unidade de massa aumenta à medida que seu tamanho é reduzido, proporcionando aumento nas forças de coesão (LOPES NETO et al., 2007).

Para os ângulos de atrito interno $(\varnothing)$ e efetivo $(\delta)$, as maiores diferenças entre as duas rações foram encontradas na condição instantânea, sendo a ração A de 12 a $14 \%$ e de 10 a $14 \%$ superior à ração $B$, para $\varnothing$ e $\delta$, respectivamente. No estado de consolidação, os resultados não diferem entre si estatisticamente, com as duas rações apresentando suas propriedades variando dentro de mesma faixa de valores. No entanto, o aumento de 7 a $13 \%$ e de 7 a $12 \%$ nos valores de $\varnothing$ e $\delta$, respectivamente, para a ração $\mathrm{B}$, no período de $12 \mathrm{~h}$ de consolidação, comparado à condição instantânea, indica que esse produto apresenta maior suscetibilidade para desenvolver coesão quando armazenado.

Entretanto, a completa compreensão desse comportamento é tarefa difícil pelo fato de existirem elementos não considerados, como conservantes, sais, ácidos, óleos e gorduras, que podem influenciar nas propriedades físicas e de fluxo de rações avícolas. Trabalhando com produtos pulverulentos, TEUNOU et al. (1999) afirmaram que pós alimentícios são complexos e de difícil caracterização pelo fato de sua composição variada, da distribuição de partículas e da presença de elementos nas fases sólida, líquida e gasosa. Somam-se a esses fatores, a variação da fração granulométrica e o efeito de "empacotamento" desenvolvido por cada ração.

$\mathrm{Na}$ Tabela 5, estão apresentados os ângulos de atrito interno do produto com as superfícies de parede analisadas $\left(\emptyset_{\mathrm{w}}\right)$ para as duas rações. Observa-se que a faixa de variação entre os valores máximos e mínimos entre as duas rações e para as duas paredes foi de 35 a 45\%, e que, em geral, os maiores resultados foram obtidos para a ração B. Quanto às diferenças entre as superfícies de parede, observaram-se maiores valores estatísticos para o aço rugoso, independentemente da ração analisada.

TABELA 5. Ângulo de atrito interno com as paredes. Wall friction angle.

\begin{tabular}{|c|c|c|c|c|}
\hline \multirow{2}{*}{ Ração } & \multicolumn{2}{|c|}{ Aço Liso } & \multicolumn{2}{|c|}{ Aço Rugoso } \\
\hline & $\varnothing_{\mathrm{wi}}$ & $\emptyset_{\mathrm{ws}}$ & $\emptyset_{\mathrm{wi}}$ & $\emptyset_{\mathrm{ws}}$ \\
\hline \multirow{2}{*}{ A } & 9,2 & 12,7 & 13,8 & 18,9 \\
\hline & \multicolumn{2}{|c|}{$10,9 \mathrm{aB}$} & \multicolumn{2}{|c|}{$16,3 \mathrm{bA}$} \\
\hline \multirow{2}{*}{ B } & 9,4 & 13,7 & 15,0 & 21,3 \\
\hline & \multicolumn{2}{|c|}{$11,5 \mathrm{aB}$} & \multicolumn{2}{|c|}{$18,1 \mathrm{aA}$} \\
\hline
\end{tabular}

Os índices "i" e "s" representam os valores inferior e superior das propriedades, respectivamente.

Letras minúsculas indicam diferença estatística nas linhas; Letras maiúsculas indicam diferença estatística nas colunas.

Na Figura 6, encontram-se as curvas representativas das Funções Fluxo (FF) para a condição instantânea $(\mathrm{t}=0)$ e de consolidação $(\mathrm{t}=12 \mathrm{~h})$ para as rações A e B. Pode-se notar que as curvas de Função Fluxo instantânea e consolidada da ração A apresentam inclinações semelhantes, com tendência de assumir a vertical com a distinção de que, para a função instantânea, os valores 
encontrados para $\mathrm{f}_{\mathrm{C}}$ são até cinco vezes maiores que os obtidos para a função fluxo consolidada, para um mesmo valor de $\sigma_{\mathrm{P}}$.

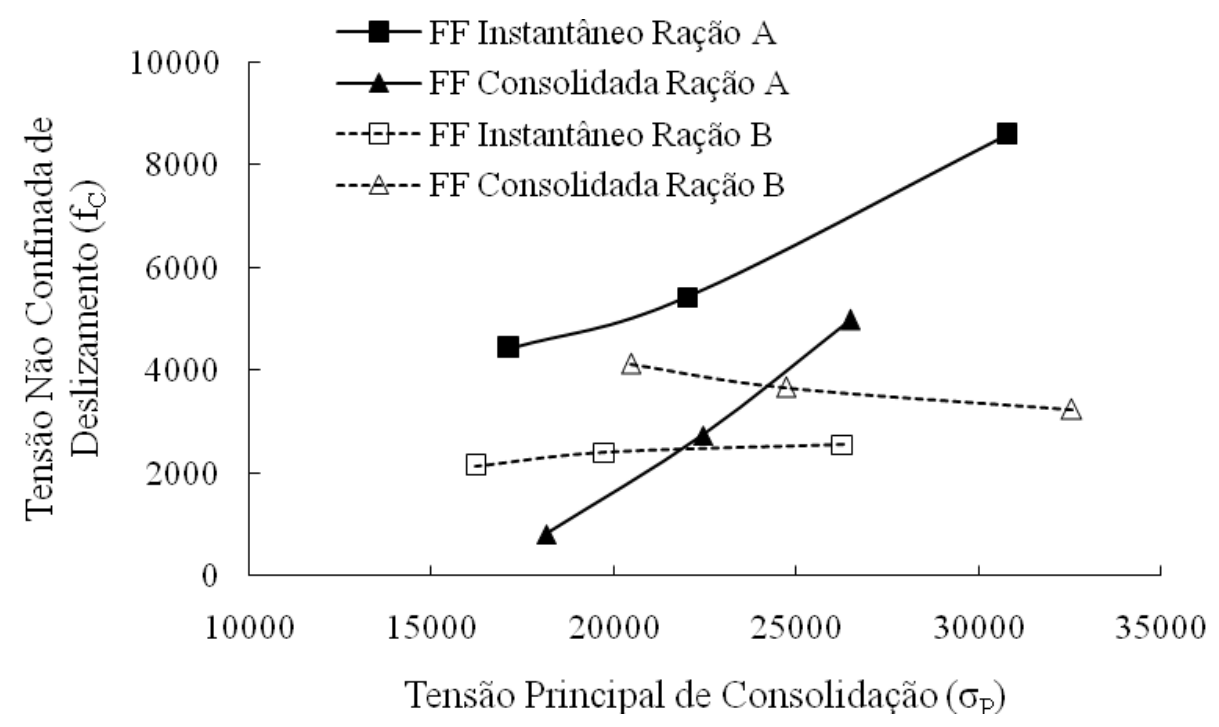

FIGURA 6. Funções-fluxo instantânea e consolidada das rações A e B. Instantaneous and consolidated flow function of $A$ and $B$ rations.

Para a condição instantânea da ração $\mathrm{B}$, a curva de FF apresenta inclinação bem menos acentuada, comparada à ração A. No entanto, a condição se inverte completamente quando analisada a curva consolidada da ração $\mathrm{B}$, que se apresenta declinada em relação ao eixo das abscissas, com os valores de fc tendo comportamento inversamente proporcional aos obtidos para $\sigma_{\mathrm{P}}$

Outra diferença marcante pode ser notada na forma como a FF das duas rações estão dispostas na Figura 6. A ração A apresenta curvas tanto instantâneas quanto consolidadas, com elevados valores de inclinação, o que indica um produto que, em função do tempo de consolidação, pode tornar-se coesivo e desenvolver problemas de fluxo. Já para a ração B, as curvas indicam tratar-se de um produto cujo fluxo está sujeito à pouca variação com o decorrer do tempo de estocagem.

A reta mais próxima à condição horizontal representa um produto de fluxo do "tipo fácil", ao passo que um produto cuja função fluxo se desloca na direção anti-horária tende a apresentar maior resistência ao escoamento (LOPES NETO et al., 2007).

RAVENET (1992) cita que, ao analisar duas curvas de Função Fluxo de um mesmo produto, uma instantânea e outra de consolidação, é possível obter diferentes valores de $\mathrm{f}_{\mathrm{C}}$ para o mesmo valor de $\sigma_{\mathrm{p}}$, muito em razão do período de consolidação, que significa o tempo em que determinada massa ficará sob ação contínua de cargas.

$\mathrm{Na}$ Tabela 6, encontram-se os valores de fator fluxo da tremonha (ff), ângulo mínimo de inclinação da tremonha com a horizontal $(\theta)$, tensão crítica não confinada $\left(\sigma_{\mathrm{cr}}\right)$, coeficiente da tremonha cônica em função de sua inclinação $\mathrm{H}(\theta)$ e orifício mínimo de descarga (D) proposto por JENIKE (1964) para as duas rações nas condições instantânea e consolidação, respectivamente, a fim de que ocorra fluxo de massa. 
TABELA 6. Características geométricas da tremonha cônica. Geometrics characteristics of conical hopper.

\begin{tabular}{|c|c|c|c|c|c|}
\hline \multicolumn{6}{|c|}{ Instantâneo $(\mathrm{t}=0)$} \\
\hline \multirow{2}{*}{ Ração } & \multicolumn{5}{|c|}{ Aço Liso } \\
\hline & ff & $\theta\left(^{\circ}\right)$ & $\sigma_{\mathrm{cr}}(\mathrm{Pa})$ & $\mathrm{H}(\theta)$ & $\mathrm{D}(\mathrm{m})$ \\
\hline $\mathrm{A}$ & 1,3 & 55,0 & 1.262 & 2,5 & 0,38 \\
\hline \multirow[t]{3}{*}{$\mathrm{B}$} & 1,4 & 55,0 & 1.249 & 2,4 & 0,37 \\
\hline & \multicolumn{5}{|c|}{ Aço Rugoso } \\
\hline & ff & $\theta\left(^{\circ}\right)$ & $\sigma_{\mathrm{cr}}(\mathrm{Pa})$ & $\mathrm{H}(\theta)$ & $\mathrm{D}(\mathrm{m})$ \\
\hline A & 1,3 & 62,5 & 1.314 & 2,4 & 0,38 \\
\hline $\mathrm{B}$ & 1,4 & 65,0 & 1.249 & 2,4 & 0,37 \\
\hline \multicolumn{6}{|c|}{ Consolidação (t = 12 h) } \\
\hline \multirow{2}{*}{ Ração } & \multicolumn{5}{|c|}{ Aço Liso } \\
\hline & ff & $\theta\left(^{\circ}\right)$ & $\sigma_{\mathrm{cr}}(\mathrm{Pa})$ & $\mathrm{H}(\theta)$ & $\mathrm{D}(\mathrm{m})$ \\
\hline A & 1,4 & 55,0 & 1.295 & 2,5 & 0,39 \\
\hline \multirow[t]{3}{*}{$\mathrm{B}$} & 1,3 & 56,0 & 1.231 & 2,5 & 0,38 \\
\hline & \multicolumn{5}{|c|}{ Aço Rugoso } \\
\hline & ff & $\theta\left({ }^{\circ}\right)$ & $\sigma_{\mathrm{cr}}(\mathrm{Pa})$ & $\mathrm{H}(\theta)$ & $\mathrm{D}(\mathrm{m})$ \\
\hline A & 1,3 & 62,4 & 1.349 & 2,4 & 0,39 \\
\hline $\mathrm{B}$ & 1,3 & 65,3 & 1.451 & 2,4 & 0,43 \\
\hline
\end{tabular}

Quando analisados os valores de inclinação da tremonha com a horizontal ( $\theta$ ), observa-se que não ocorreu variação expressiva nos ângulos para as rações $\mathrm{A}$ e B, nas duas condições de ensaio (instantâneo e consolidação), entretanto, entre paredes, para as mesmas condições de ensaio, notou-se superioridade de até $10^{\circ}$ nos valores de aço rugoso. Isso ocorreu em razão de as rações possuírem proporção significativa de partículas pequenas $(\mathrm{d}=0,6 \mathrm{~mm})$, com presença de gorduras que podem favorecer a adesão dessas na superfície. Esse fato demonstra que, apesar de o atrito com a parede ser um parâmetro dominante na determinação do ângulo mínimo da tremonha, para que ocorra fluxo (IQBAL \& FITZPATRICK, 2006), os valores encontrados não produziram variação significativa na inclinação da tremonha dentre os produtos estudados.

Ao analisarem o escoamento de rações avícolas em tremonhas metálicas, LOPES NETO et al. (2007) detectaram que, para a ocorrência de fluxo de massa, a tremonha deveria possuir ângulo mínimo de $70^{\circ}$. Já na presente pesquisa, o valor recomendado para que se assegure a ocorrência de fluxo de massa não deve ser inferior a $65^{\circ}$, sendo a discordância de valores entre as duas pesquisas decretadas, possivelmente, pelas diferenças entre o teor de gordura, uma vez que as rações analisadas na presente pesquisa apresentam teor de gordura cerca de $10 \%$ inferior aos obtidos na pesquisa de LOPES NETO et al. (2007).

Para o orifício mínimo de descarga (D), destaca-se a não ocorrência de variação significativa para as rações, nas duas superfícies de parede, e entre condições de ensaio. Apenas para a ração B, em $12 \mathrm{~h}$ de consolidação $(\mathrm{D}=0,43 \mathrm{~m}$ ), notou-se discreto aumento em razão de a função fluxo temporal desse produto possuir característica de aumento no valor de tensão não confinada, à medida que a tensão principal de consolidação é reduzida. BANDEIRA et al. (1999) ressaltam que silos para armazenamento de produtos com alto teor de gordura é necessário dimensionar-se o orifício de descarga, com área maior que a mínima recomendada pelas normas.

\section{CONCLUSÕES}

As rações A e B foram classificadas como fluxo do tipo fácil e, para o tempo de $12 \mathrm{~h}$ de consolidação, esse parâmetro não foi afetado, mesmo havendo redução do índice de fluxo $\left(\mathrm{ff}_{\mathrm{c}}\right)$. As Funções Fluxo das duas rações comportam-se de forma inversa, sendo a ração A um produto que pode, ao longo do tempo, apresentar tendência coesiva superior à ração $\mathrm{B}$. 
Quanto aos valores de coesão (C) e peso específico consolidado $(\gamma)$, encontrado para as duas rações, notou-se acréscimo de, aproximadamente, 55 e 28,6\%, respectivamente, para a condição de consolidação, indicando serem produtos suscetíveis ao aumento da coesão em função do tempo de consolidação.

Em respeito às dimensões geométricas da tremonha cônica, houve variação no ângulo mínimo de inclinação da tremonha apenas quando comparados valores entre as duas superfícies de paredes, independentemente do produto ou do tempo de consolidação.

Para a dimensão mínima do orifício de descarga, não ocorreu influência representativa da variação das propriedades de fluxo, das superfícies de paredes e das condições de ensaio adotadas nos valores obtidos, sendo recomendada para o armazenamento de rações avícolas uma inclinação de tremonha e orifício de descarga mínimos de $65^{\circ}$ e $0,43 \mathrm{~m}$, respectivamente.

\section{AGRADECIMENTOS}

Ao $\mathrm{CNPq}$, pelo apoio financeiro disponibilizado para realização desta pesquisa.

\section{REFERÊNCIAS}

ABNT. ASSOCIAÇÃO BRASILEIRA DE NORMAS TÉCNICAS. NBR 7217. Agregados. Determinação da composição granulométrica. Rio de Janeiro, 1987. 3 p.

AUSTRALIAN STANDARD 3774. Loads on bulk containers. Sydney, 1996. 65 p.

BANDEIRA, I.S.A.; NASCIMENTO, J.W.B.; SILVA, F.A.S. Análise de fluxo de ração avícola e farelo de trigo em silos prismáticos. Revista Brasileira de Engenharia Agrícola e Ambiental, Campina Grande, v.3, n.2, p.233-238, 1999.

BRITISH MATERIALS HANDLING BOARD. Draft code of practice for the design of silos, bins, bunkers and hoppers. Berkshire, 1985. 163 p.

DRESCHER, A.; WATERS, A.J.; RHOADES, C.A. Arching in hoppers: II. Arching theories and critical outlet size. Powder Technology, Lausanne, n.84, p.177-183, 1995.

ENSTAD, G.G. A novel theory on the arching and doming in mass flow hoppers. Bergen: The Michelsen Institute, 1981. $57 \mathrm{p}$.

GUAN, W.; ZHANG, Q. Consolidation and arch formation of cohesive bulk solids in storage bins. In: ANNUAL INTERNATIONAL MEETING, 22., 2005, Florida. Anais... Florida: ASAE, 2005. $10 \mathrm{p}$.

IQBAL, T.; FITZPATRICK, J. J. Effect of powder properties on the wall friction characteristics of three food powders. Journal of Food Engineering, Kidlington, v.72, n.3, p.273-280, 2006.

JENIKE, A.W. Storage and flow of silos. Salt Lake City: University of Utah, 1964. (Bulletin, 123). $48 \mathrm{p}$.

JULIANO, P.; MUHUNTHAN, B.; CÁNOVAS, G.V.B. Flow and shear descriptors of preconsolidated food powders. Journal of Food Engineering, Kidlington, v.72, n.2, p.157-166, 2006.

KHANAM, J.; NANDA A. Flow of granules through cylindrical hopper. Powder Technology, Lausanne, v.150, n.1, p.30-35, 2005.

LOPES NETO, J.P.; NASCIMENTO, J.W.B.; SILVA, V.R.; LOPES, F.F.M. Propriedade de fluxo e característica de escoabilidade de rações avícolas para dimensionamento de silos. Revista Ciência e Agrotecnologia, Lavras, v.31, n.3, p.851-859, 2007. 
MALBY, L.P.; ENSTAD, G.G.; SILVA, S.R. Investigation of the behavior of powders under and after consolidation. In: RELIABLE FLOW OF PARTICULATE SOLIDS SYMPOSIUM, 2., 1993, Oslo. Anais... 12 p.

RANDALL, E.L. Improved method for fat and oil analysis by a new process of extraction. Journal of the Analytical of Official Agricultural Chemists, Washington, v.57, n.5, p.1.167-1.168, 1974.

RAVENET, J. Silos. Barcelona: Editores Técnicos Asociados, 1992. 508 p.

TEUNOU, E.; FITZPATRICK, J.J.; SYNNOTT, E.C. Characterisation of food powder flowability. Journal of Food Engineering, Kidlington, v.39, n.1, p.31-37, 1999.

TEUNOU, E.; FITZPATRICK, J.J. Effect of time and consolidation on food powder flowability. Journal of Food Engineering, Kidlington, v.43, n.2, p.97-101, 2000. 